\title{
Reassessing the Impact of the US Fiscal Stimulus: The Role of the Monetary Policy Stance
}

\author{
Andrew Hughes Hallett ${ }^{1}$, Ansgar Rannenberg ${ }^{2}$, Sven Schreiber ${ }^{3}$ \\ ${ }^{1}$ George Mason University and University of St. Andrews, Ireland \\ ${ }^{2}$ Central Bank of Ireland, Ireland \\ ${ }^{3}$ Free University of Berlin and Macroeconomic Policy Institute of the Hans-Boeckler Foundation, Ireland \\ Correspondence: Ansgar Rannenberg, George Mason University and University of St. Andrews, Ireland.
}

Received: February 3, 2017

Accepted: February 27, 2017

Online Published: March 3, 2017

doi:10.5539/ibr.v10n4p12

URL: https://doi.org/10.5539/ibr.v10n4p12

\begin{abstract}
Cogan et al. $(2009,2010)$ claimed that the stimulus package passed by the United States Congress in February 2009 had a multiplier far below one. However, the stimulus' multiplier strongly depends on the assumed monetary policy response. Based on official statements from the Fed chairman, the general economic outlook, past behavior of the FOMC, optimal policy considerations, and from financial market expectations, we find that in February 2009, a reasonable prediction of the period of monetary accommodation would have exceeded 9 quarters. This implies that a plausible real time assessment of the stimulus' effects would have been more optimistic than Cogan et al.'s.
\end{abstract}

Keywords: Obama fiscal stimulus, fiscal multiplier, interest rate forecasts

JEL Codes: E58, E62, E37, E47

\section{Introduction}

Shortly after the stimulus package of the Obama administration (labeled American Reconstruction and Reinvestment Act, ARRA) cleared the United States Congress on February $13^{\text {th }} 2009$, Cogan et al. $(2009,2010)$ (henceforth referred to as CCTW) circulated an analysis quantifying the effects of the package on GDP and other variables using the DSGE model estimated by Smets and Wouters (2007), but restricted their simulations to the component of ARRA representing government purchases of goods and services. They found that ARRA caused a very substantial crowding out of private expenditure, implying a multiplier smaller than one, whereas the president's economic team (Bernstein and Romer (2009)) claimed a multiplier of 1.6.

There is a tension between the CCTW ex-ante estimate based on a structural model, and a number of ex-post, reduced form empirical estimates of the effect of ARRA. These studies exploit cross-state variations in ARRA spending to identify employment effects. From their estimate, Chodorow-Reich et al. (2012) derive a fiscal multiplier of 2.1. Feyrer and Sacerdote (2011) find a multiplier of 2.0 if they exclude education related grants to individual states, which they argue did not have an effect on local governments spending. Wilson (2013) estimates an employment effect of 3.4 million by 2010Q1, which is close to the effect derived by Romer and Bernstein (2009) of 3.6 million jobs saved or created, and thus consistent with their assumed spending multiplier of 1.6. ${ }^{1}$ Finally, the empirical literature on government expenditure multipliers more generally finds that they tend to be larger than one during downturns (Hughes Hallett et al. (2016) and Gechert and Rannenberg (2014)), which would also suggest more substantial effects of ARRA.

In the light these empirical results it is relevant that, as illustrated by Figure 1, ARRA's effect on GDP in the Smets and Wouters (2007) model is sensitive to the assumed length of monetary accommodation. During this period, the nominal interest rate is fixed exogenously in the CCTW simulations, whereas thereafter it responds to the simulated deviations of inflation and the output gap from their values in the absence of fiscal expansion according to the interest feedback rule suggested by Taylor (1993). Holding the interest rate constant for 4 quarters (monetary accommodation, MA=4q) as assumed in CCTW's baseline simulation of ARRA implies a crowding out of private expenditure. The reason is that

\footnotetext{
${ }^{1}$ For a more pessimistic view regarding the jobs effect, see Conley and Dupor (2013).
} 
GDP

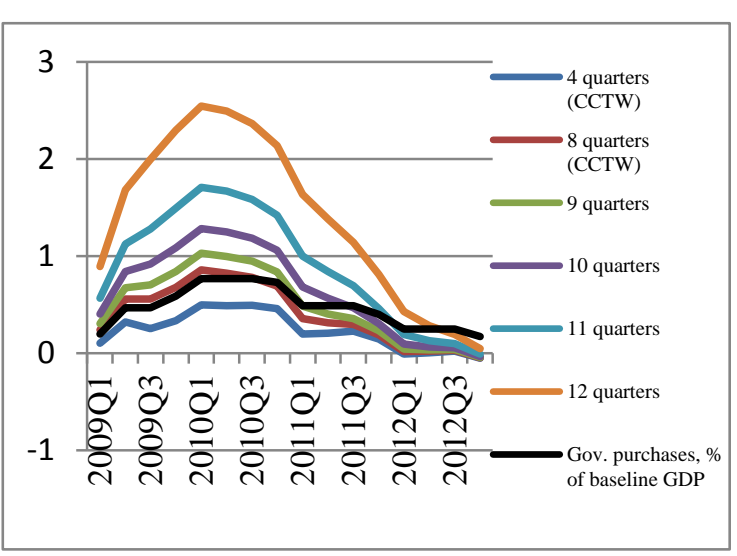

Investment

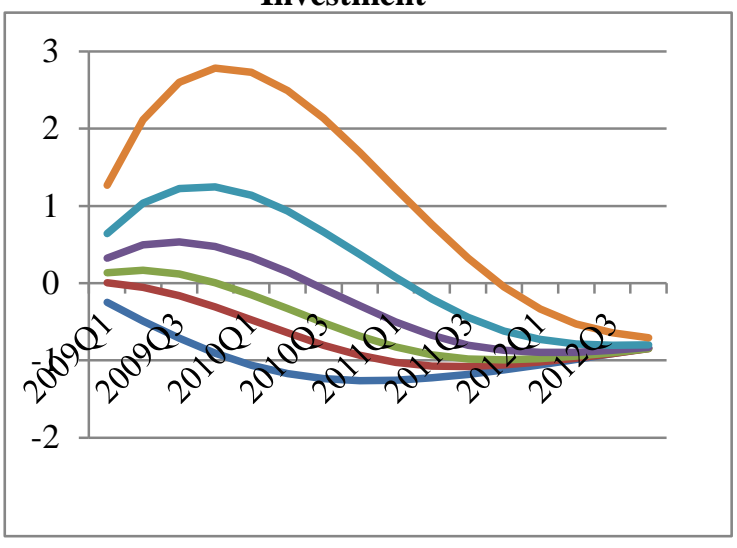

Private consumption

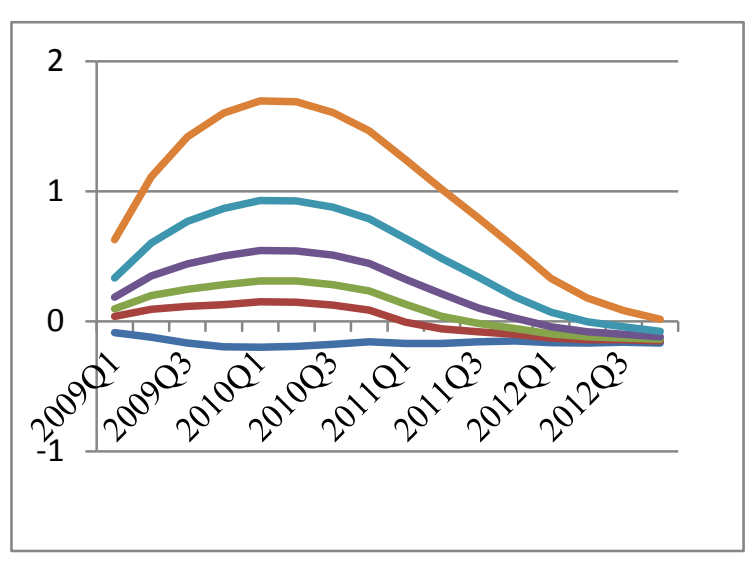

Inflation, APR

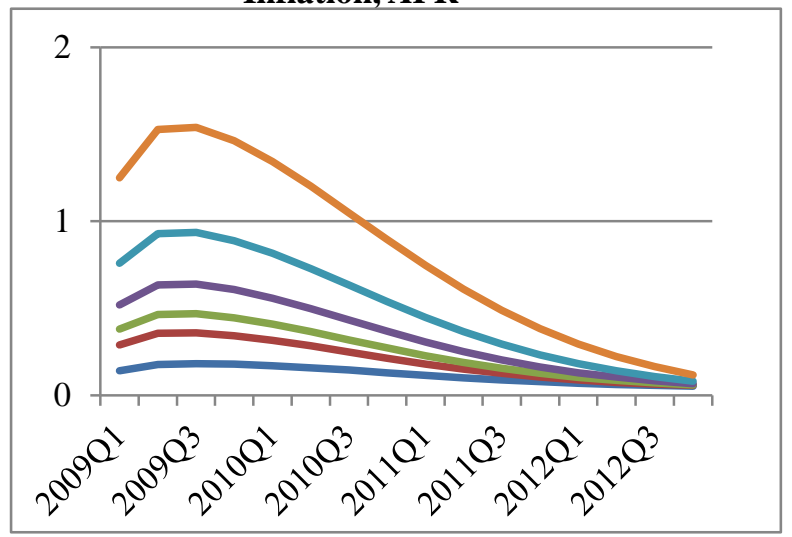

Nominal interest rate, APR

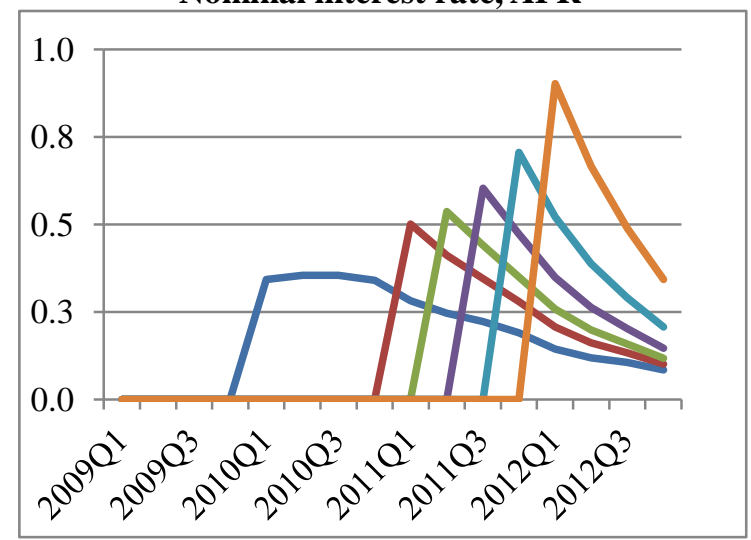

Ex-ante real interest rate, APR

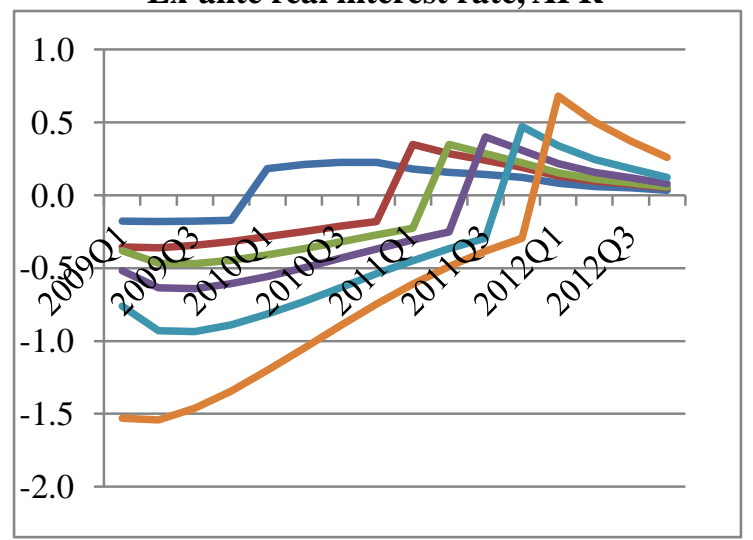

Figure 1. Effect of the increase in government purchases legislated by ARRA on GDP and other variables in the version of the Smets and Wouters (2007) used by CCTW assuming varying lengths of the period of monetary accommodation, APR=Annualized Percentage Rate

$87 \%$ of the ARRA related government expenditure increase comes online in later years, implying that the increases in inflation and the output gap it generates are met by increases in nominal and real interest rates. That leads to an overall cumulative fiscal multiplier of 0.33 (Table 1). Increasing the period of monetary accommodation to 8 quarters (a case also considered by CCTW), during which $46 \%$ of ARRA related spending comes online, lowers the real interest rate path and boosts the trajectory of private expenditure as compared to the 4 quarter case. For periods of monetary accommodation exceeding 9 quarters, the cumulative multiplier of ARRA is larger than one. A very similar argument 
concerning CCTWs results has been made by Woodford (2011), Christiano et al. (2011) and Coenen et al. (2012). ${ }^{2}$

Table 1. Cumulative multipliers, varying lengths of monetary accommodation

\begin{tabular}{ll}
\hline Number of quarters & Cumulative multiplier \\
4 (CCTW) & 0.3 \\
8 (CCTW) & 0.6 \\
9 & 0.8 \\
$\mathbf{1 0}$ & $\mathbf{1 . 1}$ \\
$\mathbf{1 1}$ & $\mathbf{1 . 5}$ \\
$\mathbf{1 2}$ & $\mathbf{2 . 5}$ \\
\hline
\end{tabular}

Note. The table reports the cumulative multiplier $m(h)=\frac{\sum_{i=1}^{h} d Y_{t+i}}{\sum_{i=1}^{h} d G_{t+i}}$, with $d Y_{t+i}$ and $d G_{t+i}$ denoting the effect of the stimulus on GDP and government spending in period $\mathrm{t}+\mathrm{i}$, respectively. $\mathrm{h}$ was set sufficiently high to ensure that $d Y_{t+h}, d G_{t+h} \approx 0$.

Both the sensitivity of the effects of ARRA in the Smets and Wouters (2007) model to the length of monetary accommodation and the discrepancy between CCTW's baseline result and the empirical ex-post evaluations cited motivate us to reexamine CCTW's justification of their assumptions regarding monetary policy. CCTW state that assuming a constant interest rate for two years, let alone for more than two years, would not be "realistic", supported by a forecasting exercise based on the model of Smets and Wouters (2007) and data up until 2009 Q1. ${ }^{3}$

As we now know, the FOMC kept the Federal Funds rate at the ZLB for seven years. Furthermore, at the end of January 2009, the Federal Reserve Banks staff's Greenbook baseline forecast predicted that the Federal Funds rate would remain at the ZLB until the end of $2012^{4}$. While the 2009 Greenbooks have only been made publicly available in 2015, Rudebusch (2009), as early as May 2009 also predicted that the Federal Funds rate would remain at the ZLB for several years. We therefore examine whether, based on information publicly available around the time ARRA was debated in the United States Congress, and with relatively simple methods, a good prediction of the period the Federal Funds rate would remain at the zero lower bound would have exceeded the one or two years assumed by CCTW. This contribution is absent from earlier analyses of CCTWs results (e.g. Woodford (2011), Christiano et al. (2011) and Coenen et al. (2012)).

Specifically, we draw on the following sources to support our argument: testimonies by the Chairman of the Federal Reserve Ben Bernanke in Congress dealing with the desirability of fiscal stimulus as a response to the financial crisis (section 1); predictions from the FOMC and private sector forecasters around the time ARRA was debated in Congress in conjunction with descriptive and econometric evidence on past interest setting behavior of the Fed (section 2, where we also comment on the interest rate forecast generated by CCTW); optimal policy considerations (section 3); and the financial market expectations embedded in implied Federal Funds Futures rates (section 4). Section 5 discusses the relation of our results to those of Swanson and Williams (2014). We conclude that, for the US economy at the beginning of 2009, a reasonable prediction of the period the Federal Funds rate would remain at its ZLB would have exceeded 9 quarters. Hence, based on the Smets and Wouters (2007) model, a less pessimistic real time assessment of the effects of the US fiscal stimulus would have been plausible.

\section{Bernanke on Fiscal Stimulus}

In this section, we evaluate two testimonies of Fed Chairman Ben Bernanke to the committee on the budget of the United States House of Representatives, one from the beginning and one from the end of 2008, to illustrate

\footnotetext{
${ }^{2}$ The model underlying the simulation results presented in Table and Figure 1 is subject to the caveat that with the exception of the interest feedback rule the, the model equations have been linearized. Therefore the model may over or underestimate the fiscal multiplier in a situation where the economy is far away from the steady state. The same is true for most contributions in this area.

${ }^{3} \mathrm{CCTW}$ also argue that a permanent interest rate peg, as assumed by Bernstein and Romer (2009), would create indeterminacy in a rational expectations model. Of course, this property does not automatically imply that the length of the peg must not exceed two years, or any other number up to the medium term.

${ }^{4}$ See the Figure on Board of Governors of the Federal Reserve System (2015) p. I-28, bottom right panel, and the associated text.
} 
the shift in Bernanke's views on the desirability of fiscal stimulus as the economic outlook darkened. In his first testimony on January $17^{\text {th }} 2008$, Bernanke (2008a) was rather skeptical. While acknowledging that fiscal stimulus "could be helpful in principle", he went out of his way to stress that a stimulus package would be desirable only if implemented very quickly, even explicitly specifying over which horizon it should be effective: Any package "should be implemented quickly and structured so that its effects on aggregate spending are felt as much as possible within the next twelve months or so ". By contrast, a stimulus that was implemented too late would be "quite counterproductive", "will not help to support economic activity in the near term", "could be actively destabilizing", and thus "any program should be explicitly temporary [...] to avoid unwanted stimulus beyond the near-term horizon".

This assessment was consistent with the economic outlook the FOMC held at the time. In January, the FOMC expected only a temporary slowdown in GDP growth and thus expected the slack in the economy to be small and of limited persistence. As Table 2 shows, the FOMC expected the unemployment gap to peak in 2008Q4 at only $0.3-0.4 \%$ and to practically vanish by the end of 2010. Correspondingly, core PCE inflation was expected to remain close to $2 \%$. With the Federal Funds rate still at $4.25 \%$, monetary policy appeared to have ample scope to stimulate the economy. At the same time, any stimulus package would have to be agreed to by a Republican president and a Democratic congress during a presidential election year. This setup was likely to lengthen the legislative process and there was a certain danger of a delayed fiscal policy response stimulating demand when slack in the economy would have vanished, which may explain why Bernanke was wary of policymakers pursuing this option.

Table 2: Unemployment gap and inflation projections of the FOMC, \%

\begin{tabular}{l|c|c|c|c|c|c}
\hline \hline & \multicolumn{3}{|c|}{ Unemployment gap } & \multicolumn{3}{c}{ Core PCE inflation } \\
\hline FOMC Meeting & Jan 17th 2008 & Oct. 20th 2008 & Jan 27th 2009 & Jan 17th 2008 & Oct. 20th 2008 & Jan 27th 2009 \\
\hline 2008 Q4 & $0.3-0.4$ & $1.4-1.6$ & & $2.0-2.2$ & $2.3-2.5$ & \\
\hline 2009 Q4 & $0.1-0.4$ & $2.2-2.7$ & $3.6-3.9$ & $1.7-2.0$ & $1.5-2.0$ & $0.9-1.1$ \\
\hline 2010 Q4 & $0-0.2$ & $1.6-2.4$ & $3.1-3.4$ & $1.7-1.9$ & $1.3-1.8$ & $0.8-1.5$ \\
\hline 2011 Q4 & - & $0.5-1.6$ & $1.8-2.6$ & & $1.3-1.7$ & $0.7-1.5$ \\
\hline
\end{tabular}

Note: The forecasts are based on the central tendency forecasts from the FOMC's Summary of Economic Projections (SEP) published after the respective meetings (FOMC (2008a), (2008b) and FOMC (2009a)). The core-PCE inflation projection is taken directly from respective SEP. The unemployment gap projection is calculated by subtracting midpoint of the central tendency projection of the long-run unemployment rate reported in the January 27-28th 2009 SEP (4.8-5\%) from the unemployment rate projection made at the respective meeting, as the FOMC started publishing projections for the longer run unemployment rate only at the January 27-28th 2009 meeting.

By contrast, in his second appearance in the House of Representatives on October $20^{\text {th }} 2008$, the chairman (Bernanke (2008b)) endorsed fiscal stimulus. After first elaborating on how the recent intensification of the financial crisis was strengthening a broad-based economic downturn, he stated that "with the economy likely to be weak for several quarters, and with some risk of a protracted slowdown, consideration of a fiscal package by the Congress at this juncture seems appropriate." In stark contrast to his dire warnings in early 2008 of a scenario where delayed fiscal stimulus would overheat the economy, on the issue of implementation speed Bernanke merely said that "To best achieve its goals, any fiscal package should be structured so that its peak effects on aggregate spending and economic activity are felt when they are most needed, namely, during the period in which economic activity would otherwise be expected to be weak." This lack of emphasis on the timing issue is all the more remarkable as a shift from a Republican to a Democratic administration was looking likely in the presidential election of November 2008, thus implying that the decision lag would be longer than in January 2008, while the overall size of the stimulus was likely to be bigger. However, Bernanke's modified message was consistent with the substantial deterioration of the FOMC's economic outlook over the course of the year. Growth throughout 2008 had strongly undershot the FOMC's expectations, and some members expected the economy to contract over the course of 2009. Therefore the FOMC now expected an unemployment gap of a substantial magnitude over a three-year horizon, with a range between $2.2-2.7 \%$ at the end of 2009 , and $0.5-1.6 \%$ by the end of 2011Q4. ${ }^{5}$ At the same time, the FOMC now expected inflation to remain significantly below $2 \%$ in 2010 and 2011. In such a scenario, even a drawn-out stimulus could stabilize the economy.

Hence the chairman's recommendations to lawmakers, in conjunction with FOMC's expectation of persistent

\footnotetext{
${ }^{5}$ As we discuss below, private sector forecasts of unemployment were even more pessimistic.
} 
downturn, are much more in line with Bernanke anticipating monetary accommodation of a stimulus package even if implemented over several years than with an expectation of a Federal Funds rate hike at the beginning of 2010 as in the CCTW baseline case. Note also that by the end of January 2009, when a first draft of ARRA had just passed the House of Representatives, the FOMC expected the unemployment gap to be substantially bigger and inflation to be substantially lower over the forecast horizon than at the time of Bernanke's second testimony (Table 2).

\section{Pre-2009 Behavior of the Federal Reserve during High Unemployment Periods}

In this section we examine how past behavior of the FOMC during periods of high unemployment could be used to forecast the path of the Federal Funds rate for the 2009-2011 period. We first discuss some descriptive evidence regarding the incidence of Federal Funds rate hikes coinciding with high real-time unemployment gaps. We then take a more formal approach and derive Federal Funds rate predictions by combining FOMC and private sector forecasts of economic activity and inflation from the time ARRA was passed with a number of established and estimated interest feedback rules.

\subsection{Some Descriptive Evidence}

At the time ARRA was making its way through Congress, the FOMC expected an unemployment gap significantly exceeding 2 percentage points at least until the end of 2011 (Table 2). It can be shown that before 2009, such conditions have very rarely been associated with a Federal Funds rate hike. To demonstrate this, we compute an unemployment gap from monthly real-time unemployment data (first releases) and the value of the long-run unemployment rate or NAIRU estimated by the staff of the Federal Reserve board and published in the Greenbook and Bluebook on the occasion of FMOC meetings, from January 1980 to December 2003. Orphanides (2001) notes that Greenbook forecasts are a useful approximation of the forecasts of the FOMC. Figure 2 plots the difference between Federal Funds target rates on the last day of a month and the last day of the previous month and the lagged unemployment gap, in order to account for the one-month publication lag of unemployment data. It turns out that Federal Funds rate hikes coinciding with an unemployment gap exceeding 1 PP are very uncommon. Indeed, they are located exclusively in the period of Paul Volcker's chairmanship, lasting from August 1979 to August 1987. Interest rate increases do not occur during the periods of high unemployment gaps in the recessions of 1990/91 or 2001. Moreover, during most of Volcker's tenure inflation was at far higher levels than anticipated for 2009-2011, and the FOMC was thus primarily focused on reestablishing price stability. Furthermore, during this era the FOMC was targeting monetary aggregates rather than directly setting the Federal Funds rate, which made the Federal Funds rate much more volatile than in earlier or later periods (B. Friedman (2005)). Hence this simple analysis of past Fed behavior suggests that the Fed typically does not tighten policy when unemployment is high unless inflation is undesirably high, implying that a Federal Funds rate hike during the 2009-2011 period was unlikely.

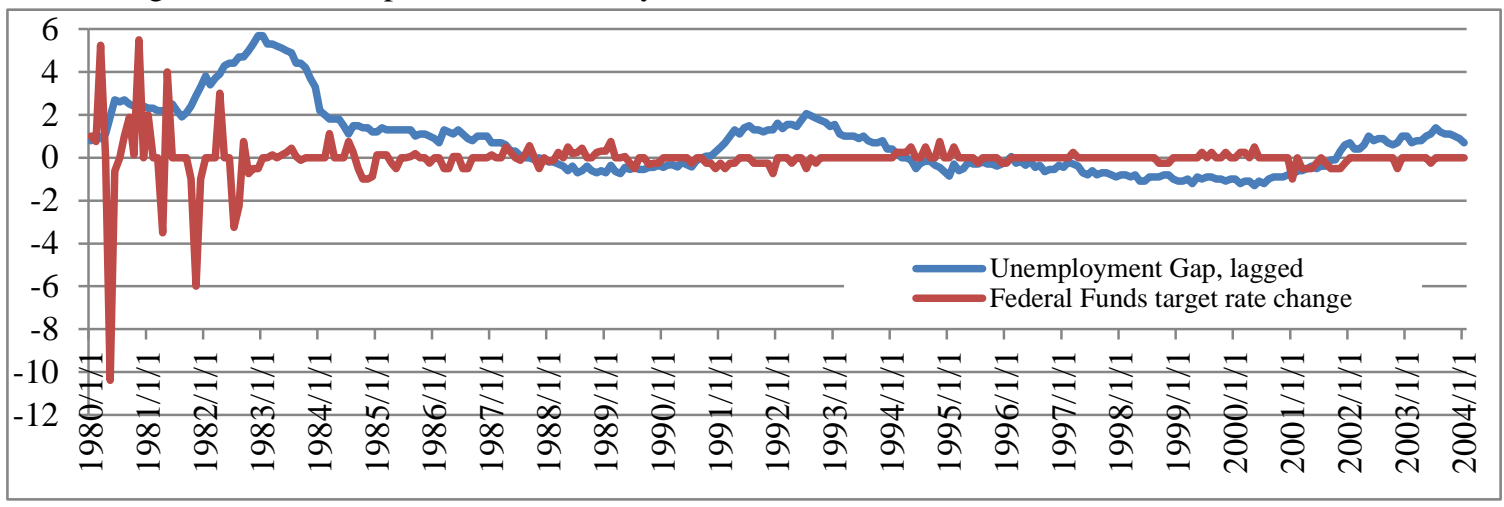

Figure 2. Unemployment gap and change in the Federal Funds target rate, $\%$

\subsection{Predictions from Interest Feedback Rules}

Since Taylor (1993), researchers have developed interest feedback rules which relate the Federal Funds rate to some measure of (current, lagged, or expected future) inflation and the output gap. We therefore compute the

${ }^{6}$ From 1980-1988, these long run unemployment rates appear in the notes attached to the table reporting the structural (or "high employment") budget deficit, which is published in at least one Greenbook each year except for 1987. From 1989-2003, we use NAIRU estimates from the Bluebook, which are provided by the Federal Reserve Bank of Philadelphia. We consider only the period up to 2003 as at the beginning of 2009 no more recent Bluebooks and Greenbooks were available due to a 5 year publication lag. 
interest rate implied by a number of such rules for the 2009-2011 period based on the expectations of the FOMC and the private sector regarding inflation and the output gap. A similar exercise was conducted by Rudebusch (2009) in May 2009, who predicted that the Federal Funds rate would remain at the zero lower bound until 2011 based on a single estimated interest feedback rule and FOMC forecasts.

While obtaining inflation expectations is straightforward, for the output gap we can only calculate expectations implied by expectations of other variables. We follow two approaches. The first uses the "gap version" of Okun's law, which relates the output gap linearly to the negative of a measure of the unemployment gap. We again define the unemployment gap as the deviation of actual unemployment from the FOMC's estimate of the long-run sustainable unemployment rate, and use an Okun coefficient of 1.88, as estimated by Lee (2000), slightly smaller than that estimated by Knotek (2007). The second approach calculates expectations of the output gap by combining an assumption concerning the output gap in 2008Q4 with predictions of actual and potential GDP growth over the forecast horizon. For details see the note below Figure 3.

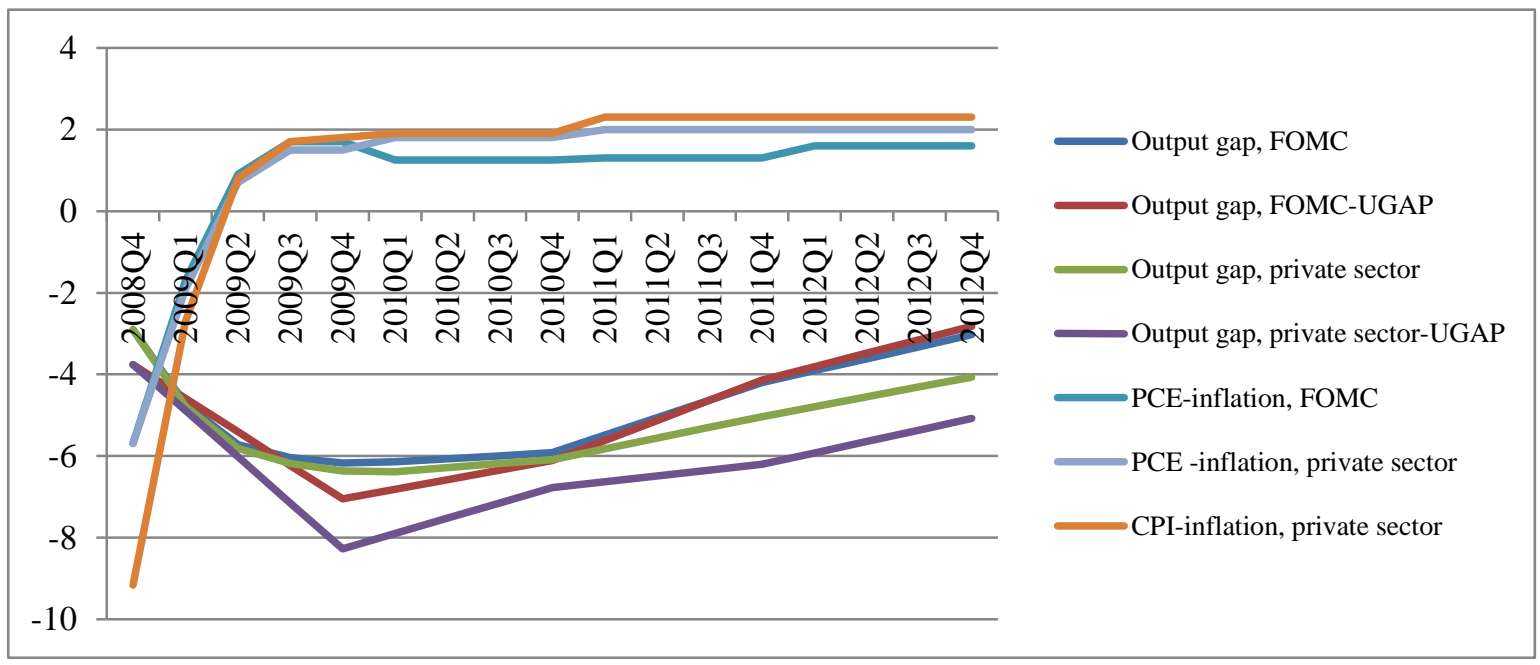

Figure 3. Implied output gap and quarterly annualized inflation expectations, $\%$

Note. Output gap paths labeled "-UGAP based" are based on the "gap version" of Okun's law, i.e. Y_GAP $(\mathrm{t})=-\mathrm{b} *(\mathrm{U}(\mathrm{t})-\mathrm{UN})$, where Y_GAP, $\mathrm{U}$ and $\mathrm{UN}$ denote the output gap, the FOMC's or the private sector's forecast of actual unemployment and the FOMC's estimate of the long-run sustainable unemployment rate, respectively, while $b=1.88$, as estimated by Lee (2000). The remaining output gap paths are calculated as the difference between actual and potential GDP. The path of potential GDP is computed using the potential growth rates reported in Table 3, and by assuming an output gap in 2008Q4 of $-2.9 \%$, which is the median of seven estimates reported by Williams and Weidner (2009), and falls short of the Congressional Budget Office's estimate of January 2009 by about one percentage point (CBO (2009)). The quarterly paths of GDP and unemployment used in these calculations, as well as the quarterly inflation paths plotted are based on the FOMC and private sector forecasts reported in Table 3. Their computation is detailed in appendices A and B.

Predictions from the FOMC and the private sector regarding inflation and unemployment as well as actual and potential GDP growth are based on the Summary of Economic Projections (SEP) produced during the FOMC's meeting on January $27^{\text {th }}-28^{\text {th }} 2009$ and on two established surveys of private-sector forecasters conducted over the following two weeks, namely the "Survey of Professional Forecasters" (SPF) and the survey conducted by Consensus Economics (Consensus Forecast (CF)). We then conduct our own calculations based on these sources and our own assumptions: see Table 3. Both FOMC members and the surveyed private-sector forecasters were assuming that a stimulus package would be passed, although its exact size and composition was uncertain at the time the forecasts were recorded. Hence any interest rate prediction generated below includes the expected effect of ARRA on the Federal Funds rate.

The resulting output gap and inflation series are displayed in Figure 3. The output gap series distilled from the expectations of the FOMC and the private sector are at first very similar but then diverge, reflecting to a large extent the more pessimistic predictions of the private sector regarding the speed of the recovery. The FOMCs 
outlook for inflation is also a bit more favorable than that of the private sector. ${ }^{7}$

Table 3: Forecasts of actual and potential GDP growth, actual and structural unemployment, and inflation, \%

\begin{tabular}{c|c|c|c|c|c|c|c|c|c|c|c|c}
\hline & \multicolumn{4}{|c|}{ GDP grow th } & \multicolumn{2}{l|}{ Pot. GDP grow th } & \multicolumn{2}{c|}{ Unemployment } & $\begin{array}{c}\text { Structural } \\
\text { unemployment, FOMC }\end{array}$ & \multicolumn{3}{c}{ Inflation, Q4/Q4 } \\
\hline Year & FOMn & CF & FOMC & CF & FOMC & CF & FOMC, Q4 & SPF/CF & & FOMC, PCE & SOP, CPI & SOP, PCE \\
\hline 2009 & 0.0 & 0.0 & -0.9 & -1.2 & 2.6 & 2.5 & 8.7 & 8.4 & 4.9 & 0.7 & 0.4 & 0.4 \\
\hline 2010 & 0.0 & 0.0 & 2.9 & 2.8 & 2.6 & 2.5 & 8.2 & 8.8 & 4.9 & 1.3 & 1.9 & 1.8 \\
\hline 2011 & 0.0 & 0.0 & 4.4 & 3.6 & 2.6 & 2.5 & 7.1 & 10.2 & 4.9 & 1.3 & 2.3 & 2.0 \\
\hline 2012 & 4.1 & 3.6 & 3.8 & 3.5 & 2.6 & 2.5 & 6.4 & 9.6 & 4.9 & 1.6 & 2.3 & 2.0 \\
\hline
\end{tabular}

Note. Forecasts labeled "FOMC" are based on the FOMC's Summary of Economic Projections made at the January 27th/28th meeting (FOMC (2009a)). Forecasts labeled CF and SF are based on the Consensus Forecasts survey of February $9^{\text {th }}$ (Consensus Economics (2009)) and the Survey of Professional Forecasters of the Federal Reserve Bank of Philadelphia of February $13^{\text {th }}$ (Federal Reserve Bank of Philadelphia (2009)), respectively. Numbers in standard print are obtained directly from the respective source, where FOMC numbers are the midpoints of the central tendency projection. Numbers in italics are calculated based on these numbers and our own assumptions. Details can be found in appendices A and B.

Figure 4 plots the Federal Funds rates implied by four different interest feedback rules using the expectations of inflation and the output gap of the FOMC and the private sector plotted in Figure 3. As we follow two approaches to calculate the output gap, each rule generates two predictions based on FOMC expectations and two predictions based on private sector expectations, thus four predictions in total. Under the rule following Taylor (1993), which is also the one used in CCTW's simulations, three of those predictions imply an exit from the ZLB in 2010Q1, as assumed by CCTW. Furthermore, the paths of the interest rate level predicted for 2010Q1 and after are sufficiently high to be consistent with the effect of ARRA on the interest rate simulated by CCTW (Figure 1). In the absence of ARRA, the path of the interest rate could have shifted downwards by the amount simulated by CCTW without hitting zero. By contrast, Orphanides' (2001) preferred interest feedback rule estimated on real-time data predicts a liftoff from the zero lower bound only in 2011Q4, with an increase of a mere $0.1 \%$.

Both the original Taylor rule and the Orphanides (2001) rule are linear in inflation and the output gap. However, there is evidence that Federal Funds rate responses to inflation and the output gap changes depend on the state of the economy. Taylor (2007) himself criticized the FOMC for keeping the Federal Funds rate several percentage points below the level prescribed by his rule for four years after the burst of the dot-com bubble. ${ }^{8}$ As the financial crisis of 2007-2009 was of much bigger proportions, an even stronger deviation was to be expected during its aftermath. Furthermore, the relationship between the level of the unemployment gap and the incidence of an interest rate increase or decrease discussed above also suggests that the interest setting behavior of the FOMC depends on the state of the economy. Therefore the other two rules we consider allow for nonlinearities. Bec et al. (2002, labeled BSC) estimate a piecewise-linear rule where the Federal Funds rate responds to one-year-ahead forecasts of inflation and the output gap and coefficients may differ depending on whether the lagged output gap is positive or negative. They find a statistically insignificant response to inflation during periods with negative output gaps. Cukierman and Muscatelli (2008, henceforth CM) allow the coefficients on one-quarter-ahead forecasts of inflation and the output gap to depend on the hyperbolical tangent of the respective target variable, and find that during the Greenspan period, the FOMC's output gap response was

\footnotetext{
${ }^{7}$ For the private sector, we plot expectations regarding both CPI and PCE-Inflation. Two of the four interest feedback rule estimates considered below, namely the rule of Bec et al. (2002) and Cukierman and Muscatelli (2008) use CPI inflation. The FOMC SEP does not contain CPI projections, so we use this measure instead. By contrast, both the original Taylor (1993) rule and the rule estimated by Orphanides (2001) refer to the GDP deflator. Since we do not have data on private sector expectations regarding this variable, we use the PCE deflator on the grounds that the average share of Personal Consumption expenditure in US GDP is close to 70\%.

${ }^{8}$ Bernanke (2010) shows that an inflation-forecast-based Taylor rule using real-time data matches the actual Federal Funds rate much better than the simple Taylor rule. However, even the rule suggested by Bernanke prescribes a path for the Federal Funds rate during the 2002Q1-2006Q1 period exceeding the actual rate by 1 percentage point or more for roughly half of the time.
} 
higher for more negative output gaps. ${ }^{9}$ Figure 4 shows that the rule estimated by CM would prescribe a negative Federal Funds rate over the whole 2009-2011 period, regardless of whether expectations are based on the SEP or the two surveys of private-sector forecasters. The BSC rule also predicts a negative rate for this period if applied to private-sector expectations. Only if applied to FOMC expectations, does it predict a liftoff from the ZLB in 2011Q1 and a level of $0.4 \%$ in 2011Q4.

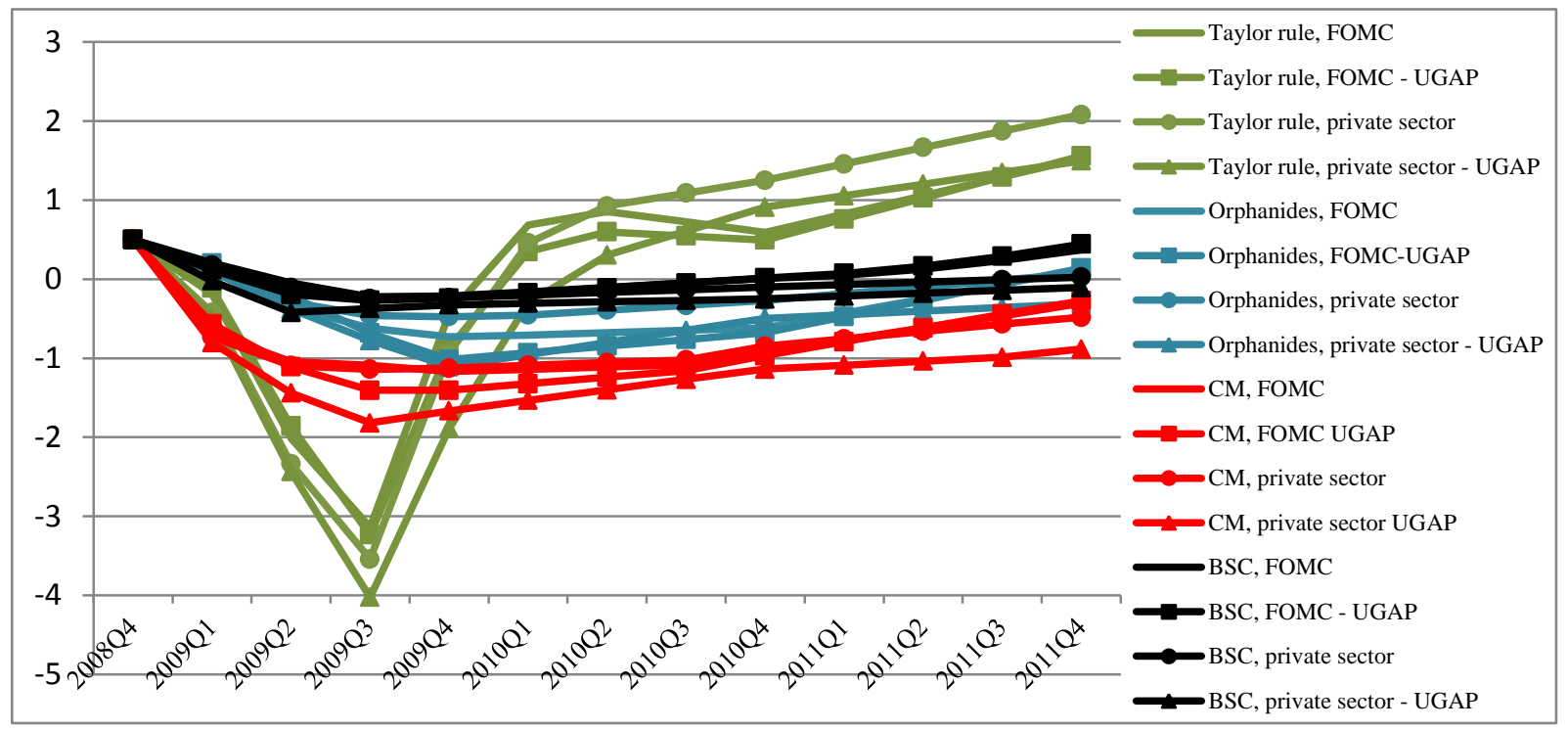

Figure 4. Federal Funds rate predicted by various interest feedback rules, $\%$

Note. This figure plots the Federal Funds rate predictions resulting from combining the Taylor (1993) interest feedback rule, one of Orphanides (2001) forward-looking interest feedback rules estimated on real time data, as well as the non-linear rules estimated by Cukierman and Muscatelli (2008) (labeled CM) and Bec et al. (2002) (labeled BSC) with the output gap and inflation expectations plotted in Figure 3. Details of the rules used are reported in Appendix C. As we consider two ways to compute implied output gap expectations for both the FOMC and private sector, we have four interest rate predictions per policy rule. When forming a prediction with rules featuring a lagged interest rate term (i.e. CM and BSC), we set the t-1 interest rate to zero whenever the interest rate predicted for period $\mathrm{t}-1$ is negative.

However, it is worthwhile noting that only part of the interest rate increase above zero observed in the FOMC expectations applied to the BSC rule can be attributed to ARRA. The reason why the BSC rule predicts an interest rate increase starting in 2011Q1 is the increase in the expected output gap in 2012. However, according to the simulation results reported above, in 2012 the output effects of ARRA were already comparatively small, even for long lengths of monetary accommodation (Figure 1). To get a rough idea of the increase in the Federal Funds rate really attributable to ARRA, we subtract the output gap increase simulated under 12 quarters of monetary accommodation from our constructed FOMC output gap expectations to get a path of the output gap with the ARRA effects cleaned out. ${ }^{10}$ We then apply this output gap path to the BSC rule to get a prediction for the path of the Federal Funds rate in the absence of ARRA, and subtract this from the path plotted in Figure 4. This procedure yields an estimate of the effect of ARRA on the Federal Funds rate. It turns out that for the 2011Q1-2011Q4 period, ARRA increased the path of the Federal Funds rate by only 0.1\%. If we redo the simulation of ARRA effects assuming that in 2011 the nominal interest rate increases exogenously by this amount while remaining constant in 2009-2010, the cumulative multiplier amounts to 2, which is still far higher

\footnotetext{
${ }^{9}$ Surico (2007) finds no evidence in favor of non-linearities over the Volcker-Greenspan period. According to Cukierman and Muscatelli (2008), pooling the terms of office of the two chairmen may be responsible for this result. Our own descriptive results on the incidence of Federal Funds rate increases presented above also suggest strong differences in the determination of the Federal Funds rate between Volcker disinflation and the period thereafter.

${ }^{10}$ We use the difference between actual and flexible-price output as a percentage of flexible-price output as the Smets and Wouter's model's equivalent to the output gap. Using the deviation of output from its steady state instead yields almost identical results.
} 
than the result of 0.3 under the CCTW baseline with four quarters of monetary accommodation.

Finally, interest rate projections based on the above rules may understate the predictable ZLB duration by disregarding the possibility of a decline of the so called natural rate of interest, i.e. the interest rate consistent with the economy operating at full potential and in the absence of transitory shocks, say as a consequence of household and firm deleveraging or a decline in the growth rate of potential GDP. A response of the Fed to such a decline would be reflected in a downward shift of its policy rule's intercept (Woodford (2001)), assumed to be constant by the authors and estimated over samples where the Federal Funds rate was on average higher than during the pre-ARRA period. Laubach and Williams (2015), using the one-sided Kalman-filter based approach of Laubach and Williams (2003), report a real-time estimate of the PCE adjusted natural interest rate of $0.4 \%$ for 2008Q4 (down from about 2.2\% two years earlier). By contrast, the (inflation-target adjusted) intercepts in the interest feedback rules used above all equal at least $2.5 \%$

Hence, by and large, applying our constructed output gap and inflation expectations to our choice of estimated policy rules yields predictions more in line with an accommodation of ARRA exceeding 9 quarters than with an accommodation lasting only one to two years.

\subsection{The Interest Rate Prediction in CCTW}

CCTW also generate an interest rate prediction of their own based on the Smets and Wouters (2007) model. More specifically, they simulate the Smets and Wouters model on US data until 2009Q1 using the Kalman filter and holding all coefficients constant. They then forecast the path of the economy with and without ARRA for the subsequent quarters for the Taylor rule and the monetary policy rule from the original version of the Smets and Wouters (2007) model. They find that with a Taylor rule, the economy never hits the ZLB, unlike our own Taylor rule based prediction discussed in the previous section, while if they use the Smets and Wouters (2007) rule, the ZLB is hit in the $2^{\text {nd }}$ and $3^{\text {rd }}$ quarters of 2009 . We will first the reasons for the difference between their Taylor rule based prediction and ours, and then discuss some more fundamental caveats of their approach.

The main reason for the different prediction is that, the intercept in CCTWs Taylor rule, i.e. the "steady-state" Federal Funds rate, is taken from Smets and Wouters (2007) and equals 6.2\%. This value is considerably higher than the value of 4.4-4.5\% we assume in section 2.2, which is based on Taylor's (1993) own suggestion that the steady-state interest rate should equal the sum of the inflation target and trend GDP growth. The higher steady state interest rate estimated by Smets and Wouters is likely due to the fact that the average Federal Funds rate during their sample period of 1966Q1-2004Q4 is of a similar magnitude. By contrast, the average Federal Funds rate during the 10 years before the outbreak of the financial crisis (1998-2007) equaled 3.8\%. If we apply the output gap values and the deviation of inflation from its target, as simulated by CCTW, to a Taylor rule with an intercept of $4.5 \%$ and an inflation target of $1.85 \%$ as assumed in our Taylor rule, the prescribed Federal Funds rate is negative for 2009Q1-2009Q3. Under the Smets and Wouters rule, it would be zero for all of 2009.

While these modified predictions still imply a liftoff after only one year, in section 2.2 we already discussed why the original Taylor rule is likely to be an unsuitable interest feedback rule for the post-2008 period. Similar criticisms apply to the rule in the Smets and Wouters (2007) model. ${ }^{11}$ Furthermore, the sample period on which the Smets and Wouters model is estimated -1966Q1-2004Q4 - is very long and likely to contain structural breaks due to changes in the monetary policy regime. For instance, according to the estimates of Cuckiermann and Muscatelli (2008), monetary policy behavior in the Volcker period differed substantially from that in the Greenspan period (1987Q4-2005Q4).

Finally, CCTW's forecast of the point of exit from the ZLB might also be downward biased as it ignores the interaction between uncertainty regarding future possibly contractionary economic shocks and the ZLB constraint. As shown by Adam and Billi (2006), if the economy is at or even above the ZLB, there is a possibility that unexpected contractionary shocks could keep the economy longer than would be the case under perfect foresight. The non-linearity associated with the ZLB implies that the distribution of future paths of the policy rate is skewed upwards and the distribution of future output and inflation paths is skewed downwards. This downward skewedness lowers the expected path of output and inflation compared to a perfect foresight scenario, and thus current output and inflation. Lower output gap and inflation would also imply a lower Fed Funds rate than simulated by CCTW.

\footnotetext{
${ }^{11}$ Like the Taylor rule, it is a linear rule unable to account for the possibility of a higher output gap response during periods of negative output gaps. Indeed, as it prescribes a positive response to the change in the output gap, it implies higher interest rates during in the presence of negative output gap levels once the output gap starts to mean-revert. Finally, it does not allow for a decline in the natural rate of interest.
} 


\section{Insights from a Simple Loss Function}

In this section, we examine how standard assumptions regarding the preferences of monetary policy makers could have been used to forecast the path of the Federal Funds rate for the 2009-2011 period. For that purpose, we assume that the FOMC was aiming to minimize the following quadratic loss function

$$
L=\sum_{t=1}^{12} \beta^{t-1} \frac{1}{2}\left(\hat{\pi}_{t}^{2}+\alpha \hat{y}_{t}^{2}\right), \alpha \geq 0, \beta \leq 1
$$

over the 12 quarters starting in 2009Q1, with $\hat{\pi}_{t}$ and $\hat{y}_{t}$ denoting respectively the annualized deviations of inflation and the output gap from their target values. We set the FOMC's inflation target equal to $1.85 \%$, which is the midpoint of the central tendency forecast for "long-run" PCE-inflation from the January 27th-28th 2009 SEP (FOMC (2009a)). We also assume that the FOMC believed, as CCTW do, the Smets and Wouters (2007) model to be a reasonable framework to assess the effects of fiscal stimulus under varying lengths of monetary accommodation.

We evaluate this loss function for the alternative inflation and output paths associated with alternative lengths of monetary accommodation $\mathrm{i}$, with $0 \leq i \leq 12$, assuming that for $t>i$, monetary policy follows the interest feedback rule in the model. For that purpose, we draw on the FOMC's inflation forecasts and the implicit output gap expectations constructed in the previous section, and plotted in Figure 5. We assume that those forecasts did not anticipate any monetary accommodation of ARRA. That means we assume that policymakers planned to respond to the effects of ARRA on inflation and GDP according to the coefficients of the Taylor rule starting in 2009Q1, rather than in 2010Q1 as assumed by CCTW.

We denote those policymaker expectations as $\hat{\pi}_{t, i=0}$ and $\hat{y}_{t, i=0}$, where $\mathrm{i}$ denotes the length of monetary accommodation. Hence for each length of monetary accommodation we can compute the paths of inflation and the output gap as $\hat{\pi}_{t, i}=\hat{\pi}_{t, i=0}+d \pi_{t, i}-d \pi_{t, 0}$ and $\hat{y}_{t, i}=\hat{y}_{t, i=0}+d y_{t, i}-d y_{t, 0}$, where $d \pi_{t, i}$ and $d y_{t, i}$ denote the simulated effects of ARRA on inflation and the output gap for $i$ quarters of monetary accommodation. ${ }^{12}$ So $d \pi_{t, i}-d \pi_{t, 0}$ and $d y_{t, i}-d y_{t, 0}$ denote the effects of increasing the length of monetary accommodation from 0 to i periods on inflation and the output gap.

Note that the press release issued after the January $27-28^{\text {th }} 2009$ FOMC meeting (FOMC (2009b)) says that "The Committee continues to anticipate that economic conditions are likely to warrant exceptionally low levels of the federal funds rate for some time." Thus, by not being stripped of the likely positive expected effects of the monetary accommodation intended by the FOMC on the path of inflation and output, our assumed values of $\hat{\pi}_{t, i=0}$ and $\hat{y}_{t, i=0}$ will be biased upwards, possibly substantially as illustrated by Figure 1. This upward bias implies that the length of monetary accommodation we find to minimize the FOMC's loss will be biased downwards, as, due to the nonlinearity of the objective, the marginal reduction in the loss caused by a given increase in inflation and output due to longer accommodation will be lower if the respective starting value is higher. To put it differently, if we were able to redo the exercise with the "true" but unknown values of $\hat{\pi}_{t, i=0}$ and $\hat{y}_{t, i=0}$, the resulting optimal length of accommodation would be longer.

Regarding $\hat{\pi}_{t, i=0}$, we assume that core PCE inflation enters the loss function, as it is the inflation measure the Fed officially uses. But we also consider PCE-inflation figures as a robustness check. Regarding $\hat{y}_{t, i=0}$, we consider both our unemployment gap-based output gap measure and the alternative. We assume a discount rate $\beta=0.99$, but our results are robust to higher values. We first consider the case where the FOMC has no preferences over output stabilization, i.e. $\alpha=0$. With such preferences the length of monetary accommodation minimizing the loss function would equal 11 quarters, rather than four as assumed by CCTW. If we use headline inflation, the optimal length of monetary accommodation would increase to 12 quarters. As can be seen in Figure 5, the FOMC expected inflation to be substantially below target over the 2009-2011 period. Therefore, the higher inflation associated with longer lengths of monetary accommodation actually helps the FOMC to meet its target.

Furthermore, if we relax the assumption that the FOMC does not care about output gap stabilization, the FOMC prefers 12 quarters of monetary accommodation to all shorter periods for any value of $\alpha>0.0089$. This threshold value is lower than what is typically used in the literature on monetary policy analysis. For instance,

\footnotetext{
${ }^{12}$ We use the difference between actual and flexible price output as a percentage of flexible price output as the Smets and Wouter's model's equivalent to the output gap; using the deviation of output from its steady state yields even stronger results.
} 
Woodford (2003) reports a value of 0.048 for his household utility-based loss function, with the underlying household preference and technology parameter values as estimated by Rotemberg and Woodford (1997). Barro and Broadbent (1997), who allow the output gap weight in the policymaker's loss function to vary freely, estimate a value of 1/3, somewhat higher than the value of 0.25 used by Jensen (2002) or McCallum and Nelson (2000) in their theoretical analysis. More recently, Chen et al. (2013) investigate the preferences of the Fed by estimating a DSGE model for various forms of optimal policy, and allow the relative weight of other objectives to follow a two-regime Markov switching process. The relative output weights equal 0.64 under the less conservative and 1.46 under the more conservative regime. In the aftermath of the dot-com crash, their estimated probability of being in the less conservative regime exceeded $50 \%$ for several years. Hence we conclude that, for reasonably parameterized preferences, the FOMC would have preferred a 12-quarter constant interest rate to all shorter lengths. If we assume a minimal degree of success of the central bank at communicating its objectives, these considerations should also have had an impact on the private sector's expectations of the path of the Federal funds rate. In the Smets and Wouters (2007) model, an anticipated length of monetary accommodation of 12 quarters would have implied multiplier comfortably above one (Table 1).

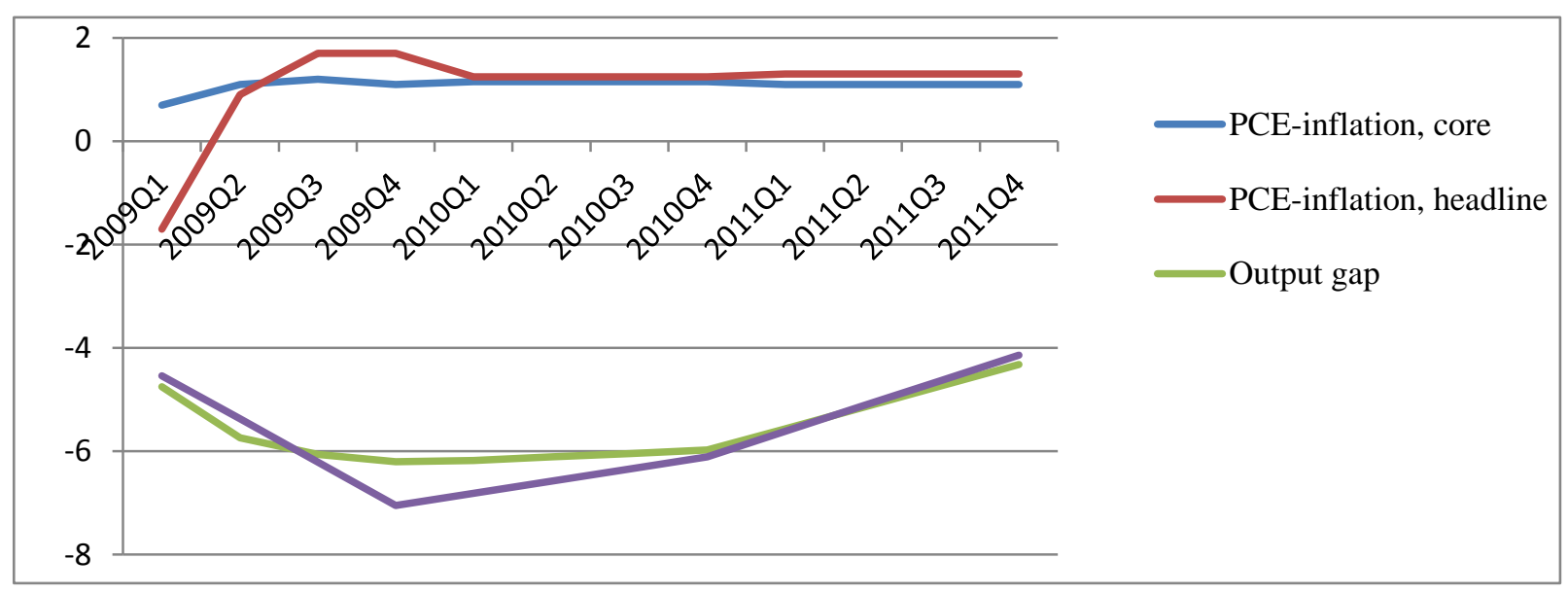

Figure 5. Inflation and implicit output gap expectations of the FOMC

Note. The paths of the output gap and PCE inflation are as in Figure 3. The path of PCE core inflation was derived in exactly the same way as the path of PCE inflation: see appendix B.

\section{Financial Market (Private Sector) Expectations}

A natural alternative to trying to predict the Federal Funds rate on the basis of the economic outlook and past systematic monetary policy responses is to derive financial market participants' expectations from Federal Funds futures (FFF). Such futures have been traded at the Chicago Board of Trade since the late 1980s. They are essentially bets on the average Federal Funds rate that prevails during month $t+n$, with the payoff given by $\left(f_{t}^{n}-r_{t+n}\right)$ times the size of the contract, where $f_{t}^{n}$ and $r_{t+n}$ denote the return fixed in the n-month FFF and the average of the Federal Funds rate prevailing in month $\mathrm{t}+\mathrm{n}$, respectively. Under the pure expectations hypothesis, $f_{t}^{n}$ would be an unbiased predictor of $r_{t+n}$. The maximum horizon of FFFs traded in the market was 24 months in 2009. In early 2009, the value of $f_{t}^{24}$ varied between 100 and 200 basis points (Figure 6), which appears to support CCTWs assumption that the Federal Funds rate would remain at zero for less than two years. 


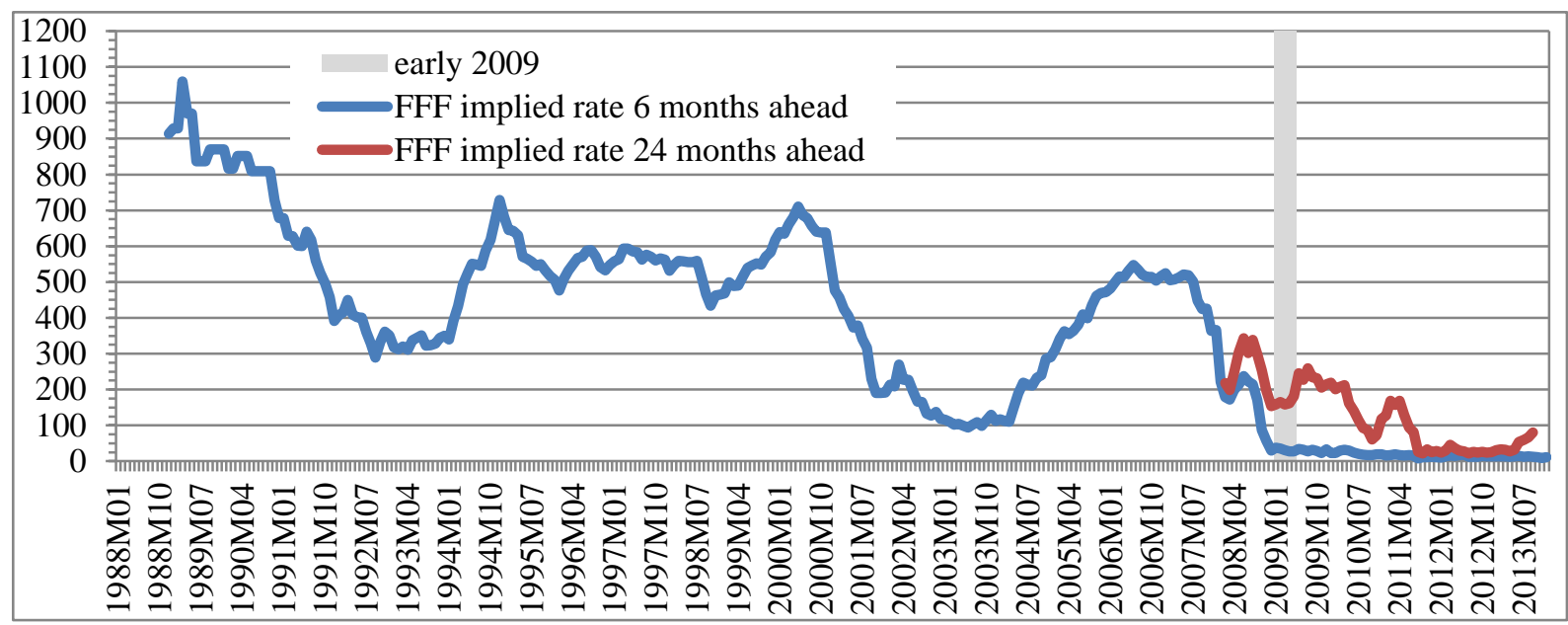

Figure 6. FFF implied rates for 6 months maturity and 24 months maturity, monthly averages of daily data, basis points

Note. The shaded area highlights the first half of 2009. Source: Macrobond.

However, Piazzesi and Swanson (2008, henceforth PS) have provided strong evidence that the failure of the pure expectations hypothesis is also true for the FFF market. They find that the excess return $\left(f_{t}^{n}-r_{t+n}\right)$ on the FFF contracts is on average positive, time-varying and partly predictable. The standard economic explanation for this phenomenon is that (time-varying) risk premia exist in asset prices. Specifically, they find that the (expected) rate of return on holding FFF contracts is negatively related to year-on-year employment (monthly non-farm payroll) growth. As employment was shrinking extraordinarily fast in the year leading up to January $2009, f_{t}^{n}$ would be expected to give an especially biased prediction of $r_{t+n}$. We therefore follow PS and estimate a forecast equation for $E_{t}\left\{f_{t}^{n}-r_{t+n}\right\}$ using data up to December 2008, and then use the relation $E_{t}\left\{r_{t+n}\right\}=$ $f_{t}^{n}-E_{t}\left\{f_{t}^{n}-r_{t+n}\right\}$ to forecast the Federal Funds rate two years ahead.

Due to the fact that 24-month FFFs were established only in 2008, we also have to follow PS and use the 6-months-ahead FFF contract in our estimation. Of course, there is a priori no direct connection with the excess returns for the 24-month horizon. However, we make use of the fact reported by PS, and by Hamilton and Okimoto (2010), that expected excess returns of FFF contracts tend to rise with the contract maturity. Assuming that this positive relationship also holds for longer maturities, our results should constitute an upper bound for the actual 24-months-ahead market expectations for the Fed funds rate.

Just as PS do, we find that lagged real-time non-farm payroll growth over the past 12 months and the implied FFF rate itself are the most important predictors of excess FFF returns, although we also experimented with term spreads, corporate bond spreads, and lagged interest rates. ${ }^{13}$ The fact that we estimate an equation suitable for forecasting in real time prevents us from using the first five lags of the dependent variable as regressors since future values of the Federal Funds rate are unknown at the time a forecast is made. We therefore use robust HAC standard errors in order to deal with residual autocorrelation.

The estimation results are reported in Table 4, and the fitted (predicted) values are compared to actual excess returns in Figure 7.

Table 4. Forecast equation for excess returns (6-month ahead horizon)

\begin{tabular}{lllll}
\hline & coefficient & std. error & t-ratio & $p$-value \\
Constant & -29.51 & 14.11 & -2.09 & 0.038 \\
$\begin{array}{l}\text { FFF implied rate 6m } \\
\text { employment growth (lagged, }\end{array}$ & 0.170864 & 0.0439514 & 3.888 & 0.000 \\
$\begin{array}{l}\text { annualized) } \\
\text { excess returns 6m (2nd lag) }\end{array}$ & -1728.37 & 593.320 & -2.913 & 0.004 \\
\hline
\end{tabular}

R-squared0.33 Adjusted R-squared 0.33

Notes. Sample 1990m1-2008m12 ( $\mathrm{T}=228)$, HAC standard errors (bandwidth 4, Bartlett kernel), Durbin-Watson-Stat: 0.29

\footnotetext{
${ }^{13}$ As in PS, we use lagged employment in order to account for the one-month publication lag.
} 
We can calculate an upper bound for $E_{t}\left\{r_{t+24}\right\}$ by plugging our estimate of the lower bound of the maturity-adjusted expected excess returns $E_{t}\left\{f_{t}^{n}-r_{t+24}\right\}$ into $E_{t}\left\{r_{t+24}\right\}=f_{t}^{24}-E_{t}\left\{f_{t}^{24}-r_{t+24}\right\}$. ${ }^{14}$ The upper bound of $E_{t}\left\{r_{t+24}\right\}$ is plotted in Figure 8, where for comparison we also include the 24-months lead of the Federal Funds rate actually realized ex post. It turns out that, after adjusting for time-varying risk premia, the two-year-ahead expectations of the Federal Funds rate hit zero in December 2008 and do not become positive again until November 2009. ${ }^{15}$

Indeed, one may argue that markets expected a zero Federal Funds rate to persist even for some time after January 2011 if the negative predicted rate were interpreted as the markets' view of the desired but practically impossible policy rate. Under this interpretation, the Federal Funds rate predicted in January 2009 to be desired for January 2011 equaled -170 basis points. A predicted negative rate of this magnitude presumably implies that market participants expected economic slack to be very high and inflation to be low by the beginning of 2011. In order to conclude that the actual Federal Funds rate would increase soon after, market participants would have had to expect a dramatic pace of recovery during 2011, which appears a priori implausible. Therefore we interpret the above results to be consistent with a horizon of a binding ZLB of more than two years, although our findings are nominally limited to two years.

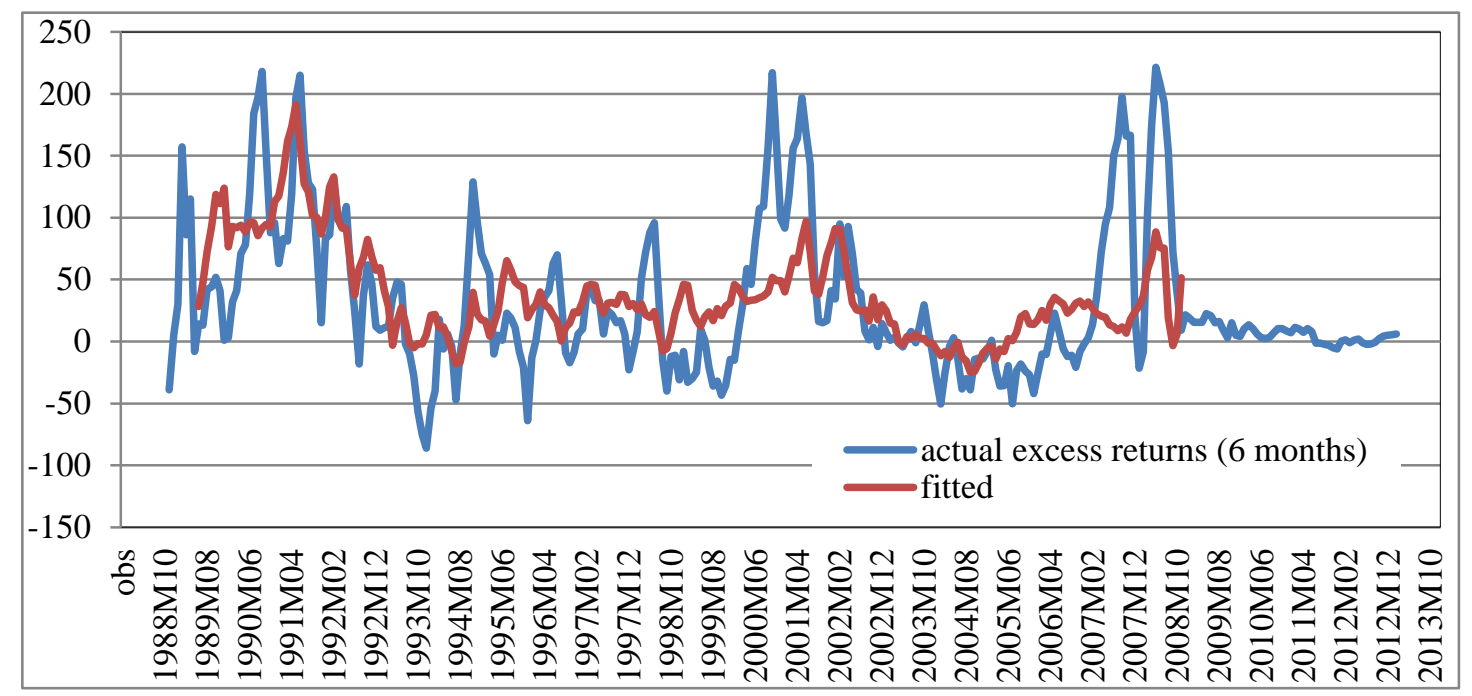

Figure 7. Predicted excess returns for the 6-month FFF contract in-sample

Note. Returns are "as is" for the 6-month horizon, i.e. not made comparable with the 24-month horizon. The time axis refers to the period of forecast formation (FFF purchase time).

\footnotetext{
${ }^{14}$ This statement refers to excess returns multiplied by the ratio of the holding periods; since the excess returns of a FFF contract with a duration of 6 months can be realized four times in a row (ceteris paribus) until the expiry of the 24-month FFF contract, we follow PS's practice and multiply the (expected) excess returns of the 6-month contract by four before subtracting it from the implied rate of the 24-month FFF contract.

${ }^{15}$ The latest available expectation in this sample is for the period August 2013 with a value of 303 basis points. This value appears quite high given the data constellation and monetary policy stance prevailing in real time, but it may be worth repeating that this constitutes just an upper bound, where the true expectation may be lower by an unknown amount.
} 


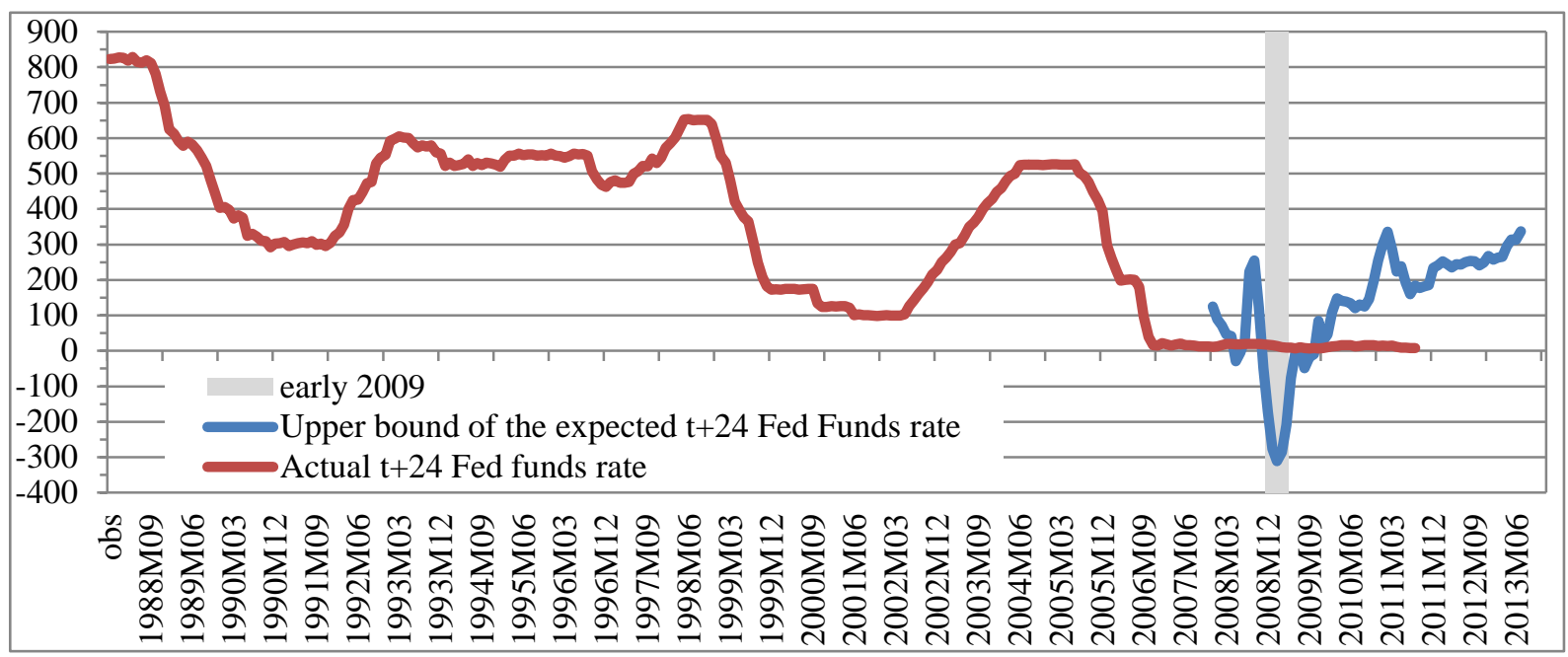

Figure 8. Expected and actual Fed funds rates, 24-months horizon

Note. The blue line is an upper bound of the Federal Funds rate expected in period $\mathrm{t}$ for $\mathrm{t}+24$, i.e. $E_{t}\left\{r_{t+24}\right\} \quad(\mathrm{see}$ the text; except when the ZLB is binding). The shaded area highlights the first half of 2009.

\section{Relation of Our Results to Swanson and Williams (2014)}

In a recent contribution, Swanson and Williams (2014) argue that the ZLB was not really restricting monetary policy during the 2009-2011 period as much as economists would have believed. Indeed, they claim that longer-term interest rates were as sensitive to news (including monetary policy actions or announcements) during much of the great recession as in normal times. This finding would imply that the fiscal policy multiplier would be more or less unaffected by the presence of the ZLB and thus would not be large. However, a closer look at their main empirical results in their Figure 3 reveals that for most of the year 2009, their sensitivity estimate for interest rates of many maturities, even including 5-year and 10-year bond yields, is essentially uninformative. The confidence band includes both the values corresponding to zero as well as to normal sensitivity, implying that neither the null of normal sensitivity (the authors hypotheses) nor the null of zero sensitivity can be rejected. The latter null implies that the ZLB was constraining monetary policy and that therefore the fiscal multiplier was large.

Moreover, the length of the period during which the confidence interval includes zero might be longer if one were to deviate from the author's choice of the period of "normal sensitivity" of bond yields to news, which Swanson and Williams (2014) assume to be 1990-2000. Their normalization choice implies that during 2000-2008, the sensitivity of two, five and ten year yields was considerably above normal (see their Figure 3). This implication appears to be at odds with the evidence that in 2004 and 2005, US long term bond yields remained low in spite of improving macroeconomic conditions and the steep tightening of US monetary policy (see Rudebusch et al. (2006)), a puzzle Alan Greenspan referred to as the "bond yield conundrum" (Greenspan (2005)). Assuming that 2000-2008 represents "normal" sensitivity would likely lengthen the period during which the hypothesis of zero sensitivity cannot be rejected.

Swanson and Williams (2014) also cite the Blue Chip Financial Forecasts survey, which contains predictions of the path of the Federal Funds rate over the current and 6 following quarters. According to the survey published on February $1^{\text {st }} 2009$, the panel on average predicted a Federal Funds rate increase above $0.25 \%$ in 2010Q1, which contradicts our own real-time forecast. ${ }^{16}$

The key question is whether the expected increase of the Federal Funds rate and the associated decline of private expenditures were due to ARRA, or whether it was part of the non-stimulus baseline of those forecasters. Throughout this paper, we have argued that based on the anticipated path of the output gap and inflation, which incorporated ARRA, a plausible prediction would have been a constant Federal Funds rate. If the Blue Chip

\footnotetext{
${ }^{16}$ Twenty-eight of the institutions covered by the panel are also included in the Survey of professional forecasters of the Federal Reserve Bank of Philadelphia, and some are also contained in the Consensus forecast survey. The Blue Chip survey also contains a consensus forecast of quarterly GDP growth until 2010Q2. The predicted GDP path closely matches the consensus of the Survey of Professional Forecasters.
} 
Forecasters expected a hike anyway, then maybe it was unrelated to their inflation and output gap projections, implying that the hike was also unrelated to ARRA. Such a conclusion would also be consistent with the finding of Swanson and Williams of a statistically insignificant response of long-term rates to macroeconomic news throughout 2009.

We have three conjectures why private-sector forecasters predicted a Federal Funds rate increase inconsistent with past Fed responses to inflation and the output gap. Firstly, a sustained period of the Federal Funds rate being at the ZLB had not occurred since the Great Depression. This experience might have made it hard for forecasters to envisage a period at the ZLB exceeding one year.

Secondly, when predicting the Fed Funds rate, private-sector forecasters might place relatively more weight on prospective GDP growth rather than on the level of GDP relative to some unobservable measure of potential output, unlike central bank or academic economists. Private-sector forecasters expected the US economy to stop contracting in 2009 Q3 (+0.9\% Annualized Percentage Rate), and expected growth to accelerate to $2.4 \%$ in 2010Q1 and 3.6\% in 2011Q1. However, as can be obtained from Figure 1, for every length of monetary accommodation considered, the bulk of the effects of ARRA on the level of GDP had already taken place by 2009Q3, with the peak effect located in 2010Q1. Hence the expected increase in the Federal Funds rate coincides with the quarter where the quarter-on-quarter growth effects of ARRA turn negative, suggesting that ARRA did not increase the Federal Funds rate expected by the Blue Chip panel even if they focused on GDP growth.

Finally, possibly being unaware of Piazzesi and Swanson (2008), Blue Chip forecasters may have placed too much weight on the prediction implied by 12 -month Federal Funds Futures, which equaled $0.62 \%$. Such reliance would tend to bias their predictions from the beginning of 2009 upwards as the strongly negative employment growth over the past 12 months increased the predictable component of excess returns. However, the size of this bias would be unrelated to ARRA as it likely had no effect on the change of employment from January 2008 to January 2009. If any of these conjectures applies, then the Blue Chip survey's prediction of a relatively early interest rate liftoff would not be attributable to ARRA and thus would not lessen the expected degree of monetary accommodation in reaction of the stimulus.

\section{Conclusion}

In this paper, we critically examine Cogan et al.'s (2010) argument that the government purchases component of the American Recovery and Reinvestment Act (ARRA) passed in February 2009 would have only a small effect on US GDP due to substantial crowding out effects. We show that this result is sensitive to the time at which the Federal Funds rate is expected to leave the ZLB, which they assume to occur in 2010Q1. What is more, drawing on official statements of the Fed chairman, predictions of FOMC members and private sector forecasters, evidence on past interest rate setting behavior of the Fed, optimal policy considerations, and financial market expectations embedded in implied Federal Funds Futures rates, we argue that a plausible prediction of the period the economy would remain at the ZLB would have exceeded nine quarters, implying some crowding-in of private expenditure and a cumulative multiplier of the increase in government consumption exceeding one.

\section{References}

Adam, K., \& Billi, R. (2007). Discretionary monetary policy and the zero lower bound on nominal interest rates. Journal of Monetary Economics, 54, 728-752. https://doi.org/10.1016/j.jmoneco.2005.11.003

Bec, F., Salem, M. B., \& Collard, F. (2002). Asymmetries in Monetary Policy Reaction Function: Evidence for U.S. French and German Central Banks. Studies in Nonlinear Dynamics \& Econometrics, 6(2). https://doi.org/10.2202/1558-3708.1006

Bernanke, B. S. (2008a). Testimony before the Committee on the Budget, U.S. House of Representatives, January 17, 2008.

Bernanke, B. S. (2008b). Testimony before the Committee on the Budget, U.S. House of Representatives, October 20, 2008.

Bernstein, J., \& Romer, C. (2009). The job impact of the Amercian recovery and reinvestment plan. Mimeo.

Board of Governors of the Federal Reserve System (2015). Greenbook Part 1, prepared for the January $27^{\text {th }} 2009$ FOMC meeting.

Board of Governors of the Federal Reserve System, Bluebook (various issues) prepared on the occasion of FOMC meetings for the 1989-2003 period.

Board of Governors of the Federal Reserve System, Greenbook (various issues) prepared on the occasion of FOMC meetings for the 1980-1988 period. 
Broadbent, B., \& Barro, R. J. (1997). Central bank preferences and macroeconomic equilibrium. Journal of Monetary Economics, 39, 17-43. https://doi.org/10.1016/S0304-3932(97)00008-1

Chen, X., Kirsanova, T., \& Leith, C. (2013). How Optimal is US Monetary Policy? Mimeo.

Chodorow-Reich, G., Feiveson, L., Liscow, Z., \& Woolston, W. G. (2012). Does state fiscal relief during recessions increase employment? Evidence from the American Reconstruction and Reinvestment Act. American Economic Journal: Economic Policy, 4(3), 118-145. https://doi.org/10.1257/pol.4.3.118

Christiano, L. J., Eichenbaum, M., \& Rebelo, S. (2011). When is the government spending multiplier large? Journal of Political Economy, 119(1), 78-121. https://doi.org/10.1086/659312

Coenen, G., Erceg, C. J., Freedman, C., Furceri, D., Kumhof, M., Lalonde, R., ......In't Veld, J. (2012). Effects of Fiscal Stimulus in Structural Models. American Economic Journal: Macroeconomics, 4(1), 22-68. https://doi.org/10.1257/mac.4.1.22

Cogan, J. F., Cwik, T., Taylor, J. B., \& Wieland, V. (2009). New Keynesian versus old Keynesian government spending multipliers. NBER Working Paper, 14782. https://doi.org/10.3386/w14782

Cogan, J. F., Cwik, T., Taylor, J. B., \& Wieland, V. (2010). New Keynesian versus old Keynesian government spending multipliers. Journal of Economic Dynamics and Control, 34, 281-295. https://doi.org/10.1016/j.jedc.2010.01.010

Congressional Budget Office. (2009). The Budget and Economic Outlook: Fiscal Years 2009 to 2019.

Conley, T. G., \& Dupor, B. (2013). The American Recovery and Reinvestment Act: Solely a government jobs program? Journal of Monetary Economics, 60(5), 535-549. https://doi.org/10.1016/j.jmoneco.2013.04.011

Consensus Economics. (2009). Consensus Forecasts, Survey date February $9^{\text {th }} 2009$.

Cukierman, A., \& Muscatelli, A. (2008). Nonlinear Taylor Rules and Asymmetric Preferences in Central Banking: Evidence from the United Kingdom and the United States. The B.E. Journal of Macroeconomics, 8(1) (Contributions), Article 7. https://doi.org/10.2202/1935-1690.1488

Federal Open Market Committee. (2008a). Minutes, Summary of Economic Projections, Meeting January 29-30 $0^{\text {th }}, 2008$.

Federal Open Market Committee. (2008b). Minutes, Summary of Economic Projections, Meeting of October $28-29^{\text {th }}, 2008$.

Federal Open Market Committee. (2009a). Minutes, Summary of Economic Projections, Meeting of January $27-28^{\text {th }}, 2008$.

Federal Open Market Committee. (2009b). Press release, Meeting of January 27-28 ${ }^{\text {th }}, 2008$.

Federal Reserve Bank of Philadelphia. (2009). Survey of Professional Forecasters, First Quarter 2009 (Release date: February 13 2009).

Feyerer, J., \& Sacerdote, B. (2011). Did the stimulus stimulate? Real time estimates of the effects of the American Recovery and Reinvestment Act. NBER Working Paper, 16759. https://doi.org/10.3386/w16759

Friedman, B. (2005). What remains of the Volcker experiment? Federal Reserve Bank of St. Louis Review, 87(2, Part 2), 323-327. https://doi.org/10.3386/w11346

Gechert, S., \& Rannenberg, A. (2014). Are Fiscal Multipliers Regime-Dependent? A Meta Regression Analysis. IMK Working Paper, 139-2014.

Gechert, S., Hughes-Hallett, A., \& Rannenberg, A. (2016). Fiscal multipliers in downturns and the effects of Eurozone consolidation, Applied Economic Letters. https://doi.org/10.1080/13504851.2015.1137545

Greenspan, A. (2005). Testimony before the Committee on Banking, Housing, and Urban Affairs, U.S. Senate, February 17, 2005.

Hamilton, J. D., \& Okimoto, T. (2010), Sources of Variation in Holding Returns for Fed Funds Futures Contracts, NBER Working Paper, 15736.

Jensen, H. (2002). Targeting nominal income growth or inflation? American Economic Review, 92(4). https://doi.org/10.1257/00028280260344533

Knotek, E. S. (2007). How Useful is Okun's Law? Federal Reserve Bank Of Kansas City. Economic Review, 2007(4), 73-103. 
Laubach, T., \& Williams, J. C. (2003). Measuring the Natural Rate of Interest. The Review of Economics and Statistics, 85(4), 1063-1070. https://doi.org/10.1162/003465303772815934

Laubach, T., \& Williams, J. C. (2015). Measuring the Natural Rate of Interest Redux. Hutchins Center Working Paper, 15.

Lee, J. (2000). The Robustness of Okun's Law: Evidence from OECD Countries. Journal of Macroeconomics, 22(2), 331-356. https://doi.org/10.1016/S0164-0704(00)00135-X

McCallum, B., \& Nelson, E. (2000). Timeless perspective vs. discretionary monetary policy in forward looking models. NBER Working paper, 7915. https://doi.org/10.3386/w7915

Orphanides, A. (2001). Monetary policy rules based on real-time data. American Economic Review, 91, 964-985. https://doi.org/10.1257/aer.91.4.964

Piazzesi, M., \& Swanson, E. T. (2008). Futures prices as risk-adjusted forecasts of monetary policy. Journal of Monetary Economics, 55, 677-691. https://doi.org/10.1016/j.jmoneco.2008.04.003

Rotemberg, J. J., \& Woodford, M. (1997). An optimization-based econometric framework for the evaluation of monetary policy. NBER Macroeconomics Annual, 12, 297-346. https://doi.org/10.1086/654340

Rudebusch, G. D. (2009). The Fed's Monetary Policy Response to the Current Crisis. FRBSF Economic Letter 2009-17.

Rudebusch, G. D., Swanson, E. T., \& Wu, T. (2006). The Bond Yield "Conundrum" from a Macro-Finance Perspective. Bank of Japan Monetary and Economic Studies (Special Edition), December 2006. https://doi.org/10.2139/ssrn.1003033

Smets, F., \& Wouters, R. (2007). Shocks and frictions in US business cycles: A bayesian DSGE approach. The American Economic Review, 97(3), 586-606. https://doi.org/10.1257/aer.97.3.586

Surico, P. (2008). The Fed's Monetary Policy Rule and US Inflation: The Case of Asymmetric Preferences. Journal of Economic Dynamics and Control, 31, 305-324. https://doi.org/10.1016/j.jedc.2005.11.001

Swanson, E. T., \& Williams, J. C. (2014). Measuring the Effect of the Zero Lower Bound On Medium- and Longer-Term Interest Rates. American Economic Review, 104(10), 3154-3185. https://doi.org/10.1257/aer.104.10.3154

Taylor, J. B. (1993). Discretion versus policy rules in practice. Carnegie-Rochester Conference Series on Public Policy, 39, 195-214. https://doi.org/10.1016/0167-2231(93)90009-L

Taylor, J. B. (2007). Housing and Monetary Policy. NBER Working paper, 13682. https://doi.org/10.3386/w13682

Williams, J. C., \& Weidner, J. (2009). How Big Is the Output Gap? FRBSF Economic Letter, 2009-19.

Wilson, D. J. (2012). Fiscal Spending Jobs Multipliers: Evidence from the 2009 American Recovery and Reinvestment Act. American Economic Journal: Economic Policy, 3(3), 251-282. https://doi.org/10.1257/pol.4.3.251

Woodford, M. (2003). Interest and Prices. Foundations for a Theory of Monetary Policy. Princeton, New Jersey, USA: Princeton University Press.

Woodford, M. (2011). Simple Analytics of the Government Expenditure Multiplier. American Economic Journal: Macroeconomics, 3, 1-35. https://doi.org/10.1257/mac.3.1.1

Woodford. (2001). The Taylor Rule and Optimal Monetary Policy. American Economic Review, 91(2), 232-237. https://doi.org/10.1257/aer.91.2.232 


\section{Appendix A: Expectations Data Sources (for Online Publication Only)}

From the FOMC's Summary of Economic Projections made at its January 27-28 2009 meeting (FOMC (2009a)), we obtain the midpoint of members' central tendency forecast for the 2009-2011 period regarding Q4/Q4 real GDP growth, Q4 unemployment, the Q4/Q4 change in the headline PCE deflator and the core PCE deflator. We also use members' estimates of the "longer run" values of GDP growth (2.6\%) and unemployment (4.9\%) as proxies for potential GDP growth and the NAIRU, respectively.

For private sector forecasts, we draw on the Consensus Forecasts survey (CF) of February $9^{\text {th }} 2009$ (Consensus Economics (2009)) and the Survey of Professional Forecasters (SPF) of the Federal Reserve Bank of Philadelphia of February 13 2009 (Federal Reserve Bank of Philadelphia (2009)). Specifically, for the 2009-2011 period we obtain year-on-year GDP growth from CF because it covers the complete 2009-2011 period, while SPF covers only the years 2009-2010 for these variables. However, year-on-year GDP growth rates projected by the SPF for 2009 and 2010 differ only marginally from those in the Consensus Forecasts (CF). Therefore, we also make use of the quarterly GDP growth forecasts published in the SPF for the 2009Q1-2010Q1 period. We also use the CF for average annual growth over the period 2012-2016 in order to construct an expected year-on-year growth rate for 2012.

Furthermore, we obtain a forecast of average annual unemployment for 2009 and 2010 from SPF, which only marginally differs from the CF, as well as quarterly unemployment rates for 2009Q1-2010Q1. For both PCE-Deflator and the CPI, we obtain quarterly growth rates for the 2009Q1-2010Q1 period as well as the Q4/Q4 change for 2009-2011 from the SPF, as the CF of consumer price inflation covers only 2009-2010. The CF survey only contains predictions regarding average annual CPI inflation and thus cannot be directly compared to the SPF forecast.

As a proxy for potential GDP growth expectations of the private sector we use the CF of average annual GDP growth during the 2017-2021 period, which equals $2.5 \%$. All forecasts cited above refer to seasonally adjusted data.

Appendix B: Construction of Expected Quarterly GDP Growth, Unemployment and Inflation Projections for 2009-2012 (for Online Publication Only)

\section{Inflation}

For the 2009Q1-2012Q4 period, FOMC expectations of quarterly PCE core and headline inflation were set as follows:

1. FOMC members' forecast Q4/Q4 inflation for 2009-2011 is reported in the SEP. For 2012, we assume that members expected $\mathrm{Q} 4 / \mathrm{Q} 4$ inflation to equal $1.6 \%$, implying that it converges halfway towards its expected long-run value of $1.85 \%$.

2. We then interpolate quarterly core and headline PCE inflation rates to match these Q4/Q4 inflation rates. For 2009Q1-2010Q1, the quarterly core and headline PCE inflation rates we set closely match the quarterly rates published in the SPF (neither the February 2009 CF survey nor the FOMC's SEP contain predictions of quarterly PCE inflation), while for the remaining period quarterly inflation rates within a given year are assumed to be identical.

We also assume that the FOMC had a good nowcast of the first estimate of the 2008Q4 value of the PCE deflator, released on January $30^{\text {th }} 2009$, which we obtain from the ALFRED Database. ${ }^{17}$

The private sector's expectations of CPI and PCE-deflator inflation are largely analogously calculated based on the SPF. Regarding 1., we assume Q4/Q4 inflation in 2012 to equal its 2011 value. The resulting year-on-year CPI-inflation for 2009 and 2010 differs only marginally from the CF.

Note our assumptions regarding 2012Q2-Q4 inflation matter only for Federal Funds rate predictions of the Orphanides et al. rule. Bec et al. (2002, labeled BSC) find a statistically insignificant and negative response to inflation during periods with a negative output gap, which is why we set the inflation response in this rule equal to zero. Regarding the Cukierman and Muscatelli (2008, labeled CM) rule, only the Federal Funds rate predicted for 2011Q4 depends on inflation expectations for 2012 - specifically the 2012Q1 forecast. The 2011Q4 prediction is very robust to the assumed 2012Q1 expected inflation rate. The interest rate predicted for 2011Q4 would turn positive only if the FOMC and the private sector expectations for 2012Q1 inflation were to exceed 3\% and $5 \%$, respectively.

\footnotetext{
${ }^{17}$ This matters only for the prediction of the simple Taylor rule for 2009Q1-2009Q3, which says that the interest rate depends on the change in the respective price index over its value in the same quarter of the previous year.
} 


\section{GDP}

FOMC expectations of quarterly GDP growth rates for the 2009Q1-2012Q4 period are constructed as follows:

1. The FOMC members' forecast Q4/Q4 GDP for 2009-2011 is reported in the SEP. For 2012, we assume that members expected the same acceleration in year-on-year GDP growth as the private sector (more on this below). This assumption implies that for 2012 (just as for 2009-2011), the FOMC is more optimistic than the private sector both regarding annual average and quarterly GDP growth.

2. We interpolate quarterly GDP growth rates to match these targets. For 2009Q1-2010Q1, the quarterly GDP growth rates we set closely match the quarterly rates published in the SPF (the FOMC's SEP does not contain predictions of quarterly growth rates), while for the remainder quarterly growth rates within a given year are assumed to be identical.

For the private sector, we proceed analogously. Regarding 1, we use the year-over-year growth rates contained in the CF survey for 2009-2011 as targets, and the first estimate of GDP inclusive of 2008Q4 GDP, released on January $30^{\text {th }} 2009$, which we obtain from the ALFRED Database.

For 2012, the year-on-year GDP growth forecast is based on the CF of average annual growth over the 2012-2016 period, which equals 2.8\%. This number translates into the expected 3.5\% for 2012 reported in Table 3 by assuming that a) forecasters did not expect GDP growth to undershoot its potential during the 2012-2016 period and b) a convergence of actual growth towards potential growth in equal-sized steps was expected to take place. Quarterly rates are then set as in step two above.

Note that regarding the interest rate rule-based Federal Funds rate predictions reported in 2.2, the expected path for 2012 GDP growth (and unemployment) matters chiefly for our 2011 interest rate prediction made with the BSC rule, which features the one-year-ahead output gap. By contrast, in the CM rule the Federal Funds rate depends on the one-quarter-ahead expected output gap. Hence only the Federal Funds rate predicted for 2011Q4 depends on output gap expectations for 2012, namely the 2012Q1 forecast.

\section{Unemployment}

Expectations of quarterly unemployment for the 2009Q1-2012Q4 period are constructed as follows:

- FOMC: When interpolating quarterly rates, we always impose that the expected unemployment rate moves from the Q4 of one year to the Q4 of the following year in equal-sized steps. FOMC members' expectations of Q4 unemployment for 2009-2011 are reported in the SEP. The Q4 2008 unemployment rate required for our computations is calculated from monthly data released on January $9^{\text {th }} 2009$, obtained from the ALFRED database. For 2012, we first calculate average annual unemployment for 2011 and then use the 2012 year-on-year GDP growth rate and Okun's law to project a 2012 average annual unemployment rate. We then set the Q4 unemployment rate such that the 2012 average annual unemployment rate equals this estimate.

- Private sector: Quarterly unemployment forecasts for the 2009Q1-2010Q1 period as well as average annual unemployment for 2010 are contained in the SPF. We construct annual average unemployment for 2011 and 2012 using Okun's law and the respective year-on-year GDP growth rates. We assume that the expected unemployment rate moves from the $\mathrm{Q} 4$ of one year to the $\mathrm{Q} 4$ of the following year in equal-sized steps, and then set the Q4 unemployment rate such that the average annual rate equals our estimate.

Whenever we use Okun's law to calculate missing unemployment expectations from the GDP growth rate expectations constructed above, we use an Okun coefficient (i.e. the effect of a percentage point change in unemployment on GDP growth in percentage points) of 1.84 as reported by Lee (2000) for annual data, and the estimates of potential GDP growth of the FOMC (2.6\%) or the private sector $(2.5 \%)$.

\section{Appendix C: Interest Feedback Rules}

In section 2.2, we consider the following four interest feedback rules, where $\pi_{t}^{\text {index }}$ and $\widehat{y_{t}}$ denote the annualized quarterly change of the respective price index used to calculate inflation and the output gap, respectively.

The simple Taylor rule is given by

$$
i_{t}=i+1.5\left(\frac{\pi_{t}^{G D P-D e f l .}+\pi_{t-1}^{G D P-D e f l .}+\pi_{t-2}^{G D P-D e f l .}+\pi_{t-3}^{G D P-D e f l .}}{4}-1.85\right)+0.5 \widehat{y_{t}}
$$

where, following Talyor (1993) $i$ equals the sum of the inflation target and trend GDP growth. Both the FOMC and the private sector are assumed to believe that the FOMC's implicit inflation target equals $1.85 \%$, the midpoint of the central tendency forecast for "long-run" PCE-inflation from the January 27th-28th 2009 SEP, while the respective potential output growth rate estimates are as reported in section 7 . 
From Table 6 of Orphanides (2001), we obtain the following rule estimated on real time data:

$$
i_{t}=0.66 i_{t-1}+(1-0.66)\left(1.8+1.64 E_{t}\left\{\frac{\pi_{t+4}^{G D P-D e f l .}+\pi_{t+3}^{G D P-D e f l .}+\pi_{t+2}^{G D P-D e f l .}+\pi_{t+1}^{G D P-D e f l .}}{4}\right\}+0.97 \widehat{y}_{t}\right)
$$

Orphanides prefers this specification because it is forward-looking and the inflation coefficient is significantly greater than one.

From Table 1 of Bec et al. (2002), we employ the estimates of their piecewise linear rule allowing for interest rate smoothing. As Bec et al. (2002) estimate their rule on monthly data, we used their estimates of the effect of the one-month and two-month lag of the Federal Funds rate on its current level rho_1 and rho_2 to compute a lagged interest rate coefficient applicable to quarterly data as (rho_1+rho_2^^3. Furthermore, we report only the estimate for the case of a negative output gap, and ignore the inflation term as its coefficient was insignificant and negative.

$$
i_{t}=0.9 i_{t-1}+(1-0.9)\left(5.262+1.237 E_{t} \hat{y}_{t+4}\right)
$$

Finally, from Table 2 of Cukierman and Muscatelli (2008), we employ the coefficient estimates reported for the Greenspan period, ignoring the term involving the hyperbolical tangent on inflation as the associated coefficient is insignificant and negative:

$$
i_{t}=0.81 i_{t-1}+(1-0.81)\left(5.279+1.01\left(E_{t} \pi_{t+1}^{C P I}-2.9\right)+0.88 E_{t} \hat{y}_{t+1}-0.84 E_{t} \hat{y}_{t+1} \operatorname{TANHYP}\left(0.2 E_{t} \hat{y}_{t+1}\right)\right)
$$

$\operatorname{TANHYP}(\ldots)$ denotes the hyperbolical tangent of the term in brackets.

\section{Copyrights}

Copyright for this article is retained by the author(s), with first publication rights granted to the journal.

This is an open-access article distributed under the terms and conditions of the Creative Commons Attribution license (http://creativecommons.org/licenses/by/4.0/). 